\title{
Anal sphincter disruption during instrumental and non-instrumental vaginal delivery
}

\author{
Samy Saad, ${ }^{a} M D$; Nancy Mohamed Ali Rund, ${ }^{b} M D ;$ Ahmed Samir Ibrahim, ${ }^{c}$ \\ MD; Khalid A Ahmad, ${ }^{c}$ MD
}

a) Department of General Surgery, Ain Shams University, Egypt.

b) Department of Obstetrics and Gynecology, Ain Shams University, Egypt.

c) Department of Radiodiagnosis, Ain Shams University, Egypt.

\begin{abstract}
Introduction: Anal sphincter trauma during childbirth represents the most important risk factor for development of fecal incontinence in women. Overt anal sphincter injury may be identified by clinical examination in 1-3\% of vaginal deliveries, but the incidence is much higher when abnormalities are specifically sought using endoanal ultrasound and anal manometry.

Aim of work: The aim of this study is to assess risk factors for sphincter damage during vaginal delivery in primiparous patients, and to assess the relationship of anal manometry and endosonography to anorectal complaints in patients who had demonstrated anal sphincter injury during vaginal delivery.

Patients \& methods: This was a prospective, observational study conducted over 130 healthy primiparous females with intact anal sphincter without history of either anorectal complaints or previous anorectal surgery. The patients were divided into: Group I: 100 patients without clinically recognized third-to fourth-degree intrapartum perineal tears. Group II: 15 primiparous patients who delivered by normal vaginal delivery, with clinically recognized third-degree perineal tears, who were examined following surgical repair by the overlapping technique. Group III: 15 primiparous patients who delivered by instrumental delivery, with clinically recognized third-degree perineal tears, who were examined following surgical repair. All patients were followed up by combined endoanal ultrasonography and anal manometry.

Results: The risk factors for the anal sphincter damage during vaginal delivery include the length of 2 nd stage if $\bullet 75$ min, absence of episiotomy, presence of shoulder dystocia, and the mode of delivery. In patients with anal sphincter damage, the maximal anal resting pressure $(M A R P)$ was significantly lower $(P<0.001)$ in patients with anorectal complaints than in those without complaints, but maximal anal squeeze pressure (MASP) was not different between groups $(P>0.05)$. Instrumental delivery $(P<0.001)$, a MARP $-30 \mathrm{mmHg}(P<0.047)$, and ultrasound evidence of combined ES $+I S$ defect $(P=0.002)$, were significantly related to anorectal complaints. MASP and ultrasound evidence of an isolated EAS defect were not found to be significantly related to anorectal complaints.

Conclusion: Knowledge of possible risk factors for the occurrence of anal sphincter injuries may therefore reduce the likelihood of faecal incontinence. Anal endosonography after vaginal delivery allows the diagnosis of clinically undetected anal sphincter damage that may be associated with subsequent fecal incontinence. Anal monometry is useful in assessment of anal sphincter disruption following vaginal delivery especially when combined with an endoanal ultrasonography.
\end{abstract}

\section{Introduction:}

Sphincter injury following labour is the most common cause of anal incontinence (including flatus) in women, which can severely diminish quality of life and lead to considerable personal and financial costs. ${ }^{1,2}$ Injury to the anal sphincter mechanism during childbirth may arise secondary to direct disruption of the 
sphincter muscles and or/traction neuropathy of the pudendal nerves. ${ }^{3}$ The conventional definitions of the 4 grades of perineal laceration (that can occur during delivery) have been supplemented by more recent modifications included in a British Royal College of Obstetricians and Gynaecologists (RCOG) guideline. ${ }^{4}$ Obstetric variables as predictors of altered faecal continence and anal sphincter injury following vaginal delivery have been reviewed in several studies and significant associations have been suggested, including increasing maternal age (over 30 years), prolonged second stage, instrumental delivery and clinically apparent anal sphincter injury at delivery. 3,5 Fynes \& his colleagues, identified full-thickness anal sphincter disruption following first vaginal delivery as the most significant risk factor for altered faecal continence $(50 \%)$ following vaginal delivery. ${ }^{6}$ MacArthur \& his colleagues surveyed 1667 postpartum women by postal questionnaire; in this cohort, $4 \%$ of women reported new symptoms of altered faecal incontinence at a mean interval of 10 months following delivery. ${ }^{7}$ Zetterstrom \& his colleagues surveyed 347 primiparous women by postpartum questionnaire where episodic frank faecal incontinence was reported in $1 \%$ of the cohort. ${ }^{8}$ Donnelly \& his colleagues, reported altered faecal continence in $25 \%$ of the women six weeks following first vaginal delivery. ${ }^{9}$ Sultan $\&$ his colleagues, identified altered faecal continence in $13 \%$ of primiparous women and $23 \%$ of multiparous women six weeks following vaginal delivery. The most common mechanism of injury in both studies was mechanical disruption of the anal sphincter muscles or combined nerve and muscle injury. ${ }^{10}$ Third-degree perineal injury is one of the most significant risk factor for faecal incontinence, with an incidence of 0.6-2.0\% following vaginal delivery. ${ }^{2}$ In contrast, pudendal nerve injury is more common with successive vaginal deliveries, which may have a cumulative effect, resulting in symptoms of altered continence many years following child birth. ${ }^{11}$ Clinical examination of the anal sphincter cannot be ever replaced by any investigation. Digital rectal examination done while asking the patient to contract the sphincters will provide not only an idea about the integrity of the puborectalis and its deficiency, but also provide an idea about the contractile power of the muscle. ${ }^{3}$ Endoanal ultrasonography is the single most useful investigation in determining the integrity of the sphincters. This can provide information about the defect in the external sphincter and its length, the maximum thickness of the external sphincter and the quality of the internal anal sphincter ring. ${ }^{3,12}$ It can also help in identification of acute obstetric occult anal sphincter injuries (OASIS), which if not identified during delivery, the women, may present later with fecal incontinence and may undergo a secondary repair. ${ }^{13,14}$ When combined with an endoanal ultrasonography, anal manometry is a useful tool in detecting anal sphincteric injury through detecting the resting and squeeze anal pressures that usually correlate with the degree of incontinence. ${ }^{3}$ Anal manometry and anal endosonography are considered the methods of choice to evaluate the condition of the anal sphincter complex. ${ }^{15,16}$ If the sphincter division is diagnosed intraoperatively, then the best results are obtained by primary suturing with 2- 0 PDS or Vicryl. If not done primary, then delayed primary or an early secondary reconstruction of the sphincter should be done. ${ }^{17}$ The aim of the present study was to assess the relationship of anal manometry and endoanal sonography to anorectal complaints in patients who had done anal sphincter repair by the overlap technique following anal sphincter injury during vaginal delivery.

\section{Patients and methods:}

This prospective observational study was conducted for the evaluation of anal sphincter changes in primiparous women during the period between October 2005 until March 2009 where 130 primiparous women delivering at Ain Shams Maternity Hospital, and Bugshan Hospital (private hospital in Saudi Arabia) were included.

The patients were divided into:

- Group I (Control): Included 100 primiparous patients without clinically recognized third to fourth degree intrapartum perineal tears who were examined 7 to 10 days following vaginal delivery. 
- Group II (Non-instrumental delivery): Included 15 primiparous patients who delivered by normal vaginal delivery, with clinically recognized third-degree perineal tears that were repaired by the overlapping technique, who were examined from 3 to 4 months following surgical repair by the overlapping technique.

- Group III (Instrumental Delivery): Included 15 primiparous patients who delivered by instrumental delivery (either forceps or vaccum), with clinically recognized thirddegree perineal tears, who were examined from 3 to 4 months following surgical repair by the overlapping technique.

Group II, and III included patients with $3 \mathrm{~b}$ or $3 \mathrm{c}$ tears according to the Royal College of Obstetricians and Gynaecologists (RCOG) classification Table(1).

Table (1): Classification of perineal injury.

\begin{tabular}{|l|l|}
\hline Injury & \multicolumn{1}{c|}{ Definition } \\
\hline First degree & Injury confined to vaginal mucosa \\
\hline Second degree & $\begin{array}{l}\text { Injury of vaginal mucosa and perineal muscles, } \\
\text { but not the anal sphincter }\end{array}$ \\
\hline Third degree & $\begin{array}{l}\text { Injury to the perineum involving the anal sphincter complex } \\
\text { (external and internal) } \\
\text { <50\% of external sphincter thickness is torn } \\
\text { 3a } 50 \% \text { of external sphincter thickness is torn } \\
\text { Internal sphincter is torn }\end{array}$ \\
\hline Fourth degree & $\begin{array}{l}\text { Injury to external and internal sphincter } \\
\text { and rectal mucosa/ anal epithelium }\end{array}$ \\
\hline
\end{tabular}

\section{Inclusion criteria:}

- Primiparity.

- Absence of previous perineal trauma, complaints of anal incontinence or previous anal surgery.

-Written informed consent for anal endosonography, and anal manometry.

If Grade 3-4 tears are confirmed by examination, the tear is repaired immediately using the overlapping technique.

\section{All patients were subjected to the following procedures: \\ 1- Full medical history:}

Mainly age, parity, onset of labour whether spontaneous or induced, instrumental delivery, past history of anorectal diseases as piles or fissures or any previous anal operation, history of fecal incontinence before delivery. Duration of 2nd stage of labour, and occurrence of shoulder dystocia were also recorded. Complaints of incontinence were scored positive if they were reported to occur more than once per week. Status of continence was evaluated 3 months and 1 year postoperatively using Cleveland Clinic Incontinence Score Table(2). ${ }^{18}$ 
Table (2): Cleveland Clinic Incontinence Score.

\begin{tabular}{l|c|c|c|c|}
\hline \multicolumn{5}{|c|}{ Cleveland Clinic Incontinence Score (CCIS) } \\
\hline & Gas & Liquid stool & Solid stool & Pad \\
\hline Occasionally & 1 & 4 & 7 & 1 \\
\hline$>$ 1/week & 2 & 5 & 8 & 2 \\
\hline Daily & 3 & 6 & 9 & 3 \\
\hline CCIS (0) : Perfect continence & $\begin{array}{l}\text { CCIS (1-7) : Good continence } \\
\text { CCIS (8-14) : Moderate incontinence }\end{array}$ \\
CCIS (21) : & Completely incontinent
\end{tabular}

\section{2- Clinical examination:}

This was done ante-partum to rule out presence of any anorectal disease or scar of previous anal operation or scar of any previous vaginal operation, or presence of old perineal tear, and post-partum to assess if both sphincters were intact Figure(1), there was a torn external sphincter Figure(2) or tears that include both internal and external sphincter Figure(3).

\section{3- Anal endosonography:}

* The endoanal ultrasound was performed to all patients of the study immediately following delivery.

* The apparatus used was Aloka TM SSD2000 ultrasonography machine. The probe is an Aloka TM ASU-64 radial $\left(360^{\circ}\right)$ scanner with frequency of $5 \mathrm{MHz}$ or $7.5 \mathrm{MHz}$ covered with a hard plastic anechoic sonolucent cover, filled with degassed waster for acoustic coupling.

\section{* Technique:}

The lubricated probe was inserted gently into the rectum then withdrawn slowly and serial images were taken at different levels. The internal anal sphincter is seen as well defined hypoechoic band, with a median thickness of $2 \mathrm{~mm}$ (range 1-3mm), while the external anal sphincter is seen as a broad echogenic band with median thickness of 6 $\mathrm{mm}$ (range 5-8mm) Figure(4). A defect in the external sphincter was defined as a break in the continuity of the normal sonographic texture of the muscle, usually with a hypoechoic appearance or an appearance of mixed echogenicity Figure(5). A defect in the internal sphincter, represented as a homogeneous hypoechoic ring, was defined as a break in the continuity of the ring Figure(6). The presence of defects at different levels of the anal canal was recorded to establish the craniocaudal length (in millimeters) of the defects. Endoanal ultrsonography were done to all patients immediately, 3 months and 1 year following overlap repair Figure(7), Figure(8).

\section{4- Anal manometry:}

Anal manometry was performed 3 to 4 months following the repair with an intracompartmental- pressure monitor (Strykler, Kalamazoo, Mich.) attached to an air-filled microballoon. The maximal anal resting pressure (MARP) and the maximal anal squeeze pressure (MASP) (i.e the maximal increase above the resting pressure) were measured according to a stationary pull through technique.

* Technique:

Anal manometry was performed with the patient in the left lateral position with flexed knees and hips, without bowel preparation. A catheter of 3-mm diameter with a microtransducer was placed in the rectum and left to acclimate for several minutes. The catheter was then withdrawn in 1-cm steps. Maximum anal resting pressure (MARP), expressed in $\mathrm{mmHg}$, was determined by pulling the catheter through the anal canal three times and calculating the mean value of the three measurements. After the transducer was positioned at the location of the MARP, the patient was asked to squeeze maximally three times to obtain the maximum anal squeeze pressure (MASP), expressed in $\mathrm{mmHg}$. The mean value of three recordings was taken as the MASP. 


\section{Exclusion Criteria:}

- Any anorectal disease.

- Previous anal operation.

- Previous vaginal operation.

- Previous uterine scar.

- Women delivered or planned to be delivered by Cesarean section.

- Multiple pregnancy.

- Structural deformities of the pelvis (e.g Polio...)

- Epidural blockade during the second stage of labour.

- Abnormal fetal lie.

- History of fecal incontinence.

\section{Primary repair:}

All patients with anal sphincter tear were repaired primarily immediately postpartum, using the overlapping technique. Both ends of healthy EAS were mobilized to do overlap. We avoided excessive mobilization of the sphincter not to jeopardize its blood supply. Both external and internal anal sphincters were repaired when concomitantly injured. Overlap repair with good bulk of both ends of the external sphincter was performed by using $2 / 0$ polyproline mattress sutures achieving a snug anal opening while the damaged internal sphincter was repaired with a running continuous suture of 2-0 polyglycolic acid (Vicryl). Vaginal mucosa, perineal body, and perineal skin were repaired as usual in seconddegree perineal rupture or episiotomy. The skin was loosely approximated in a manner to increase perineal body length and allow adequate drainage of the repair. Wound was daily dressed and the patients were on fluid diet for 4 days postoperatively, then started normal diet and continued on laxative 2 weeks postoperatively. All patients received prophylactic antibiotic treatment.

\section{Statistical analysis:}

Data were entered on a personal computer, held data base, and the data were analyzed with Statistical Package of Social Sciences version 11, (SPSS INC Chicago,III).

\section{Results:}

Clinical aspects of labour and delivery

The demographic characteristics and basic clinical aspects of labour and delivery of all patients of the study $(n=130)$ are detailed in Table(3).

Table (3): Demographic characteristics and labour and delivery details of all patients of the study $(n=130)$.

\begin{tabular}{|l|c|c|c|}
\hline & $\begin{array}{c}\text { Group I (n=100) } \\
\text { Mean } \pm \text { SD or \% }\end{array}$ & $\begin{array}{c}\text { Group II (n=15) } \\
\text { Mean } \pm \text { SD or \% }\end{array}$ & $\begin{array}{c}\text { Group III (n=15) } \\
\text { Mean } \pm \text { SD or \% }\end{array}$ \\
\hline Maternal age (years) & $27.4 \pm 5.1$ & $28.3 \pm 5.9$ & $26.3 \pm 4.7$ \\
GA (weeks) & $38.5 \pm 1.5$ & $39.2 \pm 1.3$ & $38.2 \pm 1.6$ \\
Birth weight (kgm) & $3.2 \pm 0.4$ & $3.3 \pm 0.4$ & $3.5 \pm 0.3$ \\
Length of 2nd stage of labour (min) & $66.5 \pm 36.5$ & $107.1 \pm 52.7$ & $104 \pm 50.4$ \\
Labour onset: & $87(87 \%)$ & $10(66.7 \%)$ & $12(80 \%)$ \\
-Spontaneous & $13(13 \%)$ & $5(33.3 \%)$ & $3(20 \%)$ \\
-Induced & $10(10 \%)$ & $4(26.7 \%)$ & $3(20 \%)$ \\
Occipitoposterior: & $90(90 \%)$ & $11(73.3 \%)$ & $12(80 \%)$ \\
-Yes & & & \\
-No & $79(79 \%)$ & $15(100 \%)$ & $0(0 \%)$ \\
Mode of delivery: & $8(8 \%)$ & $0(0 \%)$ & $11(73.3 \%)$ \\
-Non-instrumental & $13(13 \%)$ & & $4(26.7 \%)$ \\
-Forceps & & & $8(53.3 \%)$ \\
-Ventouse & $64(64 \%)$ & $10(66.7 \%)$ & $7(46.7 \%)$ \\
Episiotomy: & $36(36 \%)$ & $5(33.3 \%)$ & $2(13.3 \%)$ \\
-Yes & $1(1 \%)$ & $2(13.3 \%)$ & $13(86.7 \%)$ \\
-No & $99(99 \%)$ & $13(86.7 \%)$ & \\
Shoulder dystocia: & &
\end{tabular}


There was no statistical significant difference between those with 3rd degree perineal tear (Group II, and III), and the control group (Group I) regarding the maternal age, and gestational age at the time of delivery $(\mathrm{P}>0.05)$.
Length of 2nd stage of labour was longer in Group II (non-instrumental delivery + 3rd degree anal sphincter) $(107.1 \pm 52.7)$, than in Group I (control) (66.5 \pm 36.5$), \mathrm{P}<0.01$. While, there was no statistical significant difference between both groups, regarding fetal birth weight, labour onset, episiotomy, shoulder dystocia ( $>>0.05)$ Table(4).

Table (4): Comparison between Group I (control), and Group II (non-instrumental delivery + 3rd degree perineal tear).

\begin{tabular}{|l|c|c|c|c|}
\hline & $\begin{array}{c}\text { Group I (n=100) } \\
\text { Mean } \pm \text { SD or \% }\end{array}$ & $\begin{array}{c}\text { Group II (n=15) } \\
\text { Mean } \pm \text { SD or \% }\end{array}$ & $\begin{array}{c}\text { P } \\
\text { value }\end{array}$ & Significance \\
\hline Birth weight (kgm) & $3.2 \pm 0.4$ & $3.3 \pm 0.4$ & $>0.05$ & NS \\
Length of 2nd stage of labour (min) & $66.5 \pm 36.5$ & $107.1 \pm 52.7$ & $<0.01$ & S \\
Labour onset: & $87(87 \%)$ & $10(66.7 \%)$ & $>0.05$ & NS \\
-Spontaneous & $13(13 \%)$ & $5(33.3 \%)$ & & \\
-Induced & $10(10 \%)$ & $4(26.7 \%)$ & $>0.05$ & NS \\
Occipitoposterior: & $90(90 \%)$ & $11(73.3 \%)$ & & \\
-Yes & $79(79 \%)$ & $15(100 \%)$ & $>0.05$ & NS \\
-No & $8(8 \%)$ & $0(0 \%)$ & & \\
Mode of delivery: & $13(13 \%)$ & & & \\
-Non-instrumental & & & NS \\
-Forceps & $64(64 \%)$ & $10(66.7 \%)$ & $>0.05$ & \\
-Ventouse & $36(36 \%)$ & $5(33.3 \%)$ & & \\
Episiotomy: & $1(1 \%)$ & $2(13.3 \%)$ & $>0.05$ & NS \\
-Yes & $99(99 \%)$ & $13(86.7 \%)$ & & \\
-No & & \\
Shoulder dystocia: & & & \\
-Yes & & & \\
-No & & & & \\
\hline
\end{tabular}

$N S=$ non-significant, $S=$ significant. 
Length of 2nd stage of labour was longer in Group III (Instrumental delivery + 3rd degree anal sphincter injury)( $104 \pm 50.4)$, than in Group I (control) (66.5 \pm 36.5$), \mathrm{P}<0.001$. While, there was no statistical significant difference between both groups, regarding birth weight, labour onset, episiotomy and shoulder dystocia (P>0.05) Table(5).

Table (5): Comparison between Group I (control), and Group III (Instrumental delivery + 3rd degree perineal tear).

\begin{tabular}{|l|c|c|c|c|}
\hline & $\begin{array}{c}\text { Group I (n=100) } \\
\text { Mean + SD or \% }\end{array}$ & $\begin{array}{c}\text { Group III (n=15) } \\
\text { Mean + SD or \% }\end{array}$ & $\begin{array}{c}\text { P } \\
\text { value }\end{array}$ & Significance \\
\hline Birth weight (kgm) & $3.2 \pm 0.4$ & $3.5 \pm 0.3$ & $>0.05$ & NS \\
Length of 2nd stage of labour (min) & $66.5 \pm 36.5$ & $104 \pm 50.4$ & $<0.001$ & HS \\
Labour onset: & $87(87 \%)$ & $12(80 \%)$ & $>0.05$ & NS \\
-Spontaneous & $13(13 \%)$ & $3(20 \%)$ & & \\
-Induced & $10(10 \%)$ & $3(20 \%)$ & $>0.05$ & NS \\
Occipitoposterior: & $90(90 \%)$ & $12(80 \%)$ & & \\
-Yes & $79(79 \%)$ & $0(0 \%)$ & $<0.001$ & HS \\
-No & $8(8 \%)$ & $11(73.3 \%)$ & & \\
Mode of delivery: & $13(13 \%)$ & $4(26.7 \%)$ & & \\
-Non-instrumental & & & \\
-Forceps & $64(64 \%)$ & $8(53.3 \%)$ & $>0.05$ & NS \\
-Ventouse & $36(36 \%)$ & $7(46.7 \%)$ & & \\
Episiotomy: & $1(1 \%)$ & $2(13.3 \%)$ & $>0.05$ & NS \\
-Yes & $99(99 \%)$ & $13(86.7 \%)$ & & \\
-No & & & \\
Shoulder dystocia: & & & \\
-Yes & & & \\
-No & & & & \\
\hline
\end{tabular}

$N S=$ non-significant,$S=$ significant, $H S=$ Highly significant . 
Of the 100 patients in Group I with uncomplicated vaginal delivery, 13 had vaccum delivery, 8 forceps delivery and 79 had noninstrumental vaginal delivery.

Of the 100 patients in Group I with uncomplicated vaginal delivery, 10 (10\%) women were recognized as having sonographic signs that resembled findings in cases with confirmed sphincter damage when examined following delivery where four women were found to have a suspected external sphincter defect, and in six women a combined external and internal sphincter defect was suspected.

The ten women were excluded as a control group on recognition of the sonographic signs suspicious for occult sphincter defect. The following table shows the general characteristics and labour delivery details of such patients with an occult sphincteric defect Table(6).

Table (6): Characteristics and labour and delivery details of women in Group I with occult sphincteric tears $(n=10)$.

\begin{tabular}{|c|c|c|c|c|c|c|c|c|}
\hline Case & $\begin{array}{c}\text { Age } \\
\text { (year) }\end{array}$ & $\begin{array}{c}\text { GA } \\
\text { (week) }\end{array}$ & $\begin{array}{c}\text { Birth } \\
\text { weight } \\
\text { (kgm) }\end{array}$ & $\begin{array}{c}\text { Length } \\
\text { of 2nd } \\
\text { stage } \\
\text { (min) }\end{array}$ & $\begin{array}{c}\text { Instrumental } \\
\text { delivery }\end{array}$ & Episiotomy & $\begin{array}{c}\text { Clinical } \\
\text { diagnosis }\end{array}$ & US \\
\hline 1 & 23 & 39 & 3.35 & 125 & - & - & Grade 1 & IS + ES \\
2 & 32 & 38 & 3.85 & 49 & forceps & + & Grade 2 & IS + ES \\
3 & 28 & 40 & 3.44 & 159 & - & - & Grade 1 & IS + ES \\
4 & 35 & 41 & 3.22 & 150 & forceps & + & Grade 2 & IS + ES \\
5 & 29 & 39 & 3.08 & 73 & - & - & Grade 1 & IS + ES \\
6 & 32 & 40 & 3.33 & 170 & forceps & + & Grade 2 & IS + ES \\
7 & 33 & 39 & 3.15 & 39 & - & - & Grade 2 & ES \\
8 & 29 & 38 & 3.12 & 110 & - & + & Grade 2 & ES \\
9 & 24 & 40 & 2.60 & 26 & ventouse & - & Grade 1 & ES \\
10 & 33 & 40 & 3.87 & 72 & - & - & Grade 1 & ES \\
\hline
\end{tabular}

IS= Internal Sphincter, ES= External Sphincter. 
Fetal birth weight and length of the 2nd stage of labour, were found to be higher in those with 3rd degree perineal tear than in those with no defects ( $\mathrm{P}<0.001$ for both). In addition, the fetal head position, mode of delivery, and presence of dystocia were found to be of statistical significance on comparing those with 3rd degree perineal tear with the control group $(\mathrm{P}<0.05, \mathrm{P}<0.001,<0.001$ respectively). There was no statistical significant difference regarding the maternal age and the onset of labour, on comparing those with 3rd degree perineal tear with the control group; as shown in Table(7).

Table (7): Comparison between those with no sphincter defects $(n=90)$, and those with 3rd degree perineal tear $(n=30)$.

\begin{tabular}{|c|c|c|c|c|}
\hline & $\begin{array}{l}\text { No Defects }(n=90) \\
\text { Mean } \pm \text { SD or } \%\end{array}$ & $\begin{array}{c}\text { Defects }(n=30) \\
\text { Mean } \pm \text { SD or } \%\end{array}$ & $\begin{array}{c}\mathbf{P} \\
\text { value }\end{array}$ & Significance \\
\hline Maternal Age (years) & $27.1 \pm 5.1$ & $27.9 \pm 5.1$ & $>0.05$ & NS \\
\hline GA (weeks) & $38.4 \pm 1.5$ & $38.8 \pm 1.4$ & $>0.05$ & NS \\
\hline Birth weight (kgm) & $3.2 \pm 0.4$ & $3.4 \pm 0.4$ & $<0.001$ & HS \\
\hline Length of 2 nd stage of labour (min) & $63.0 \pm 32.9$ & $103.5 \pm 50.6$ & $<0.001$ & HS \\
\hline Labour onset: & & & & \\
\hline -Spontaneous & $79(87.8 \%)$ & $22(73.3 \%)$ & $>0.05$ & NS \\
\hline -Induced & $11(12.2 \%)$ & $8(26.7 \%)$ & & \\
\hline Occipitoposterior: & & & & \\
\hline -Yes & $8(8.9 \%)$ & $2(6.6 \%)$ & $<0.05$ & $S$ \\
\hline -No & $82(91.1 \%)$ & $28(93.4 \%)$ & & \\
\hline Mode of delivery: & & & & \\
\hline -Non-instrumental & $73(81.1 \%)$ & $15(50 \%)$ & $<0.001$ & HS \\
\hline -Forceps & $5(5.6 \%)$ & $11(36.6 \%)$ & & \\
\hline -Ventouse & $12(13.3 \%)$ & $4(13.4 \%)$ & & \\
\hline Episiotomy: & & & & \\
\hline -Yes & $60(66.7 \%)$ & $16(53.3 \%)$ & $>0.05$ & NS \\
\hline$-\mathrm{No}$ & $30(33.3 \%)$ & $14(46.7 \%)$ & & \\
\hline Shoulder dystocia: & & & & \\
\hline -Yes & $1(1.1 \%)$ & $4(13.3 \%)$ & $<0.001$ & HS \\
\hline -No & $89(98.9 \%)$ & $26(86.7 \%)$ & & \\
\hline
\end{tabular}

$N S=$ non significant, $S=$ significant, $H S=$ highly significant.

Logistic stepwise mutiregression analysis of all patients of the study $(n=130)$, shows that the most independent predictors for the sphincteric damage are the following, as shown in Table(8):

- Length of 2 nd stage if $\bullet 75$ min which is the cut off point, after which there is more risk of developing perineal tear $(\mathrm{P}<0.0000)$, (OR 5.2, 95\% CI 2.3-11.5).
- Episiotomy, where there is decreased risk of perineal tears with the presence of episiotomy ( $\mathrm{P}<0.0044)$, (OR -0.6, 95\% CI 0.2-1.3).

- Shoulder dystocia, where its presence will increase the risk for perineal tears $(\mathrm{P}<0.00012)$, (OR 15.7, 95\% CI 1.8-135.3).

- Mode of delivery, where is increased risk for developing perineal tear with forceps delivery ( $\mathrm{P}<0.0001)$, (OR 13.3, 95\% CI 7.7-23).

Table (8): Logistic Multiregression analysis for all patients of the study, regarding the risk for developing perineal tear.

\begin{tabular}{|l|c|c|c|c|}
\hline & Regression coefficient & P value & F ratio & P value \\
\hline Length of 2nd stage (min) & 0.0049 & 0.0000 & & \\
Mode of delivery: & 0.0612 & 0.0001 & 18.67 & $<0.0000$ \\
Forceps & -0.2094 & 0.0044 & & \\
Non-forceps & 0.6066 & 0.00012 & & \\
Episiotomy & & & \\
Shoulder dystocia &
\end{tabular}


Clinical assessment of the anorectal complaints:

Thirty patients presented with overt anal sphincteric injury, $18(60 \%)$ presented with Grade $3 \mathrm{~b}$ perineal tear, and $12(40 \%)$ patients presented with Grade 3c perineal tear. All patients were repaired immediately by the overlap technique. A total of 19 patients $(65 \%)$ presented 1-3 months later with anorectal complaints. Of these, 7 reported incontinence to liquid stools 1 to 6 times per week, 4 reported incontinence to gas and liquid stools 1 to 5 times per day, and 8 reported the same complaint more than 5 times a day. In these patients, the mean CCIS at 3 months postpartum was 10 (7-14). At 12 months postoperatively, there was marked improvement of continence in patients with anorectal complaints, where the mean score dropped to 4 (0-10) Table(9).

Table (9): Mean Cleveland Clinic Incontinence Score (CCIS).

\begin{tabular}{|l|c|c|}
\hline \multicolumn{2}{|c|}{ Anal sphincter damage } \\
\hline & $\begin{array}{c}\text { With complaint } \\
\mathbf{n = 1 9}\end{array}$ & $\begin{array}{c}\text { Without complaint } \\
\mathbf{n = 1 1}\end{array}$ \\
\hline $\begin{array}{l}\text { Mean CCIS } \\
\text { at 3 months }\end{array}$ & $10(7-14)$ & $3(0-6)$ \\
$\begin{array}{l}\text { Mean CCIS } \\
\text { at 12 months }\end{array}$ & $4(0-10)$ & $1(0-4)$ \\
\hline
\end{tabular}

\section{Endoanal ultrasonography:}

Of the 130 women, $18(13.8 \%)$ had combined defects of ES+IS, while 22 (16.9\%) had an isolated external sphincteric defect.

Univariate analysis of the factors were studied in relationship to the presence of anorectal complaints mainly incontinence symptoms.

In the univariate analysis, instrumental delivery $(\mathrm{P}<0.001)$, a resting anal pressure - $30 \mathrm{mmHg}(\mathrm{P}<0.047)$, and ultrasound evidence of combined ES + IS defect $(\mathrm{P}=0.002)$, were significantly related to anorectal complaints (fecal urgency, anal incontinence..)
Maximal anal squeeze pressure and ultrasound evidence of an isolated EAS defect (regardless of extent or thickness) were not found to be significantly related to anorectal complaints on univariate analysis.

When adjusted for all other factors using multiple logistic regression analysis, only instrumental delivery (OR 3.1, 95\% CI 1.27.9) and the presence of combined IS+ES defect shown by endoanal ultrasound (OR 5.1, 95\% CI 1.5-22.9) remained significantly and independently related to anorectal complaints.

\section{Anal manometry:}

Demographic data of the anal manometry that was done for all patients of the study are shown in Table(10).

Table (10): Anal manometry results for all patients of the study (n=130).

\begin{tabular}{|l|c|c|c|}
\hline \multicolumn{1}{|c|}{ Anal Manometry } & $\begin{array}{c}\text { Group I (n=100) } \\
\text { Mean } \pm \text { SD or \% }\end{array}$ & $\begin{array}{c}\text { Group II (n=15) } \\
\text { Mean } \pm \text { SD or \% }\end{array}$ & $\begin{array}{c}\text { Group III (n=15) } \\
\text { Mean } \pm \text { SD or \% }\end{array}$ \\
\hline Anal length (cm) & $3.0 \pm 0.2$ & $1.3 \pm 0.4$ & $1.3 \pm 0.3$ \\
MARP (mmHg) & $48.2 \pm 14.3$ & $22.5 \pm 4.6$ & $23.1 \pm 4.6$ \\
MASP (mmHg) & $101.3 \pm 30.5$ & $42.3 \pm 4.5$ & $44.7 \pm 6$ \\
Anorectal complaints: & $8(8 \%)$ & $10(66.7 \%)$ & $9(60 \%)$ \\
- Yes n(\%) & $92(92 \%)$ & $5(33.3 \%)$ & $6(40 \%)$ \\
- No n(\%) & & & \\
\hline
\end{tabular}


Both MARP and MASP were significantly lower in patients with anal sphincter damage

than in controls Table(11).

Table (11): Comparative analysis between those with no sphincteric damage $(n=90)$, and those with $3 r d$ degree perineal tear $(n=30)$, regarding the anal manometry results.

\begin{tabular}{|l|c|c|c|c|}
\hline Anal manometry & $\begin{array}{c}\text { Control } \\
(\mathbf{n = 9 0 )}\end{array}$ & $\begin{array}{c}\text { 3rd degree } \\
\text { perineal tear } \\
(\mathbf{n = 3 0})\end{array}$ & P-value & Significance \\
\hline Anal length $(\mathrm{cm})$ & $3.0 \pm 0.1$ & $1.7 \pm 0.8$ & $<0.0001$ & HS \\
MARP (mmHg) & $51.2 \pm 11.6$ & $22.4 \pm 4.7$ & $<0.0001$ & HS \\
MASP (mmHg) & $107.9 \pm 24.4$ & $43.2 \pm 5.2$ & $<0.0001$ & HS \\
\hline
\end{tabular}

$N S=$ non significant, $S=$ significant, $H S=$ highly significant .

In the group of patients with anal sphincter damage and anorectal complaints, 9 (41 percent) had an MARP that is usually considered abnormally low $(<30 \mathrm{~mm} \mathrm{Hg}$ ), and 16 (73 percent) had an abnormal MASP $(<70 \mathrm{~mm} \mathrm{Hg})$, whereas none of the controls had an abnormal MARP and only 1 had an MASP below $70 \mathrm{~mm} \mathrm{Hg}(\mathrm{P}<0.05$ and $\mathrm{P}<0.001$, respectively).
In patients with anal sphincter damage, MARP was significantly lower $(\mathrm{P}<0.05)$ in patients with anorectal complaints $(22.4 \pm 4.7 \mathrm{mmHg})$ than in those without complaints $(48.2 \pm 14.3 \mathrm{mmHg})$, but MASP was not different between groups $(\mathrm{P}>0.05)$; Table(12).

Table (12): Comparison between the number of patients with anal sphincter damage with anorectal complaints and those without, regarding MARP, and MASP.

\begin{tabular}{|c|c|c|c|c|}
\hline \multicolumn{3}{|c|}{ Anal sphincter damage } & \multirow[b]{2}{*}{ P-value } & \multirow[b]{2}{*}{ Significance } \\
\hline & $\begin{array}{c}\text { With complaint } \\
n=19\end{array}$ & $\begin{array}{l}\text { Without complaint } \\
n=11\end{array}$ & & \\
\hline $\begin{array}{l}\text { MARP }<30 \mathrm{mmHg} \\
\mathrm{n}(\%)\end{array}$ & $9(41 \%)$ & $2(18.2 \%)$ & $<0.05$ & S \\
\hline $\begin{array}{l}\text { MASP<70mmHg } \\
\text { n }(\%)\end{array}$ & $16(73 \%)$ & $7(63.6 \%)$ & $>0.05$ & NS \\
\hline
\end{tabular}

$N S=$ non significant, $S=$ significant, $H S=$ highly significant .

When patients with anal sphincter damage without complaints were compared with controls, only the number of patients with an abnormal MASP differed significantly between both groups (64 vs. 8 percent; $\mathrm{P}<0.05$ ). 


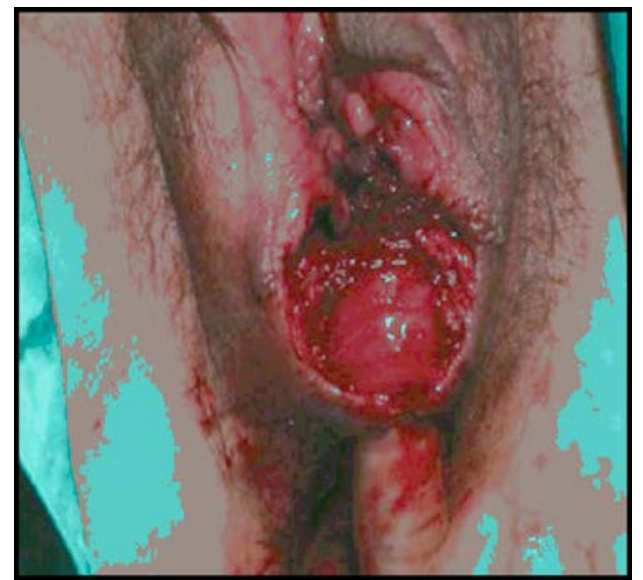

Figure (1): Episiotomy with an intact anal sphincter demonstrated during a digital rectal examination.

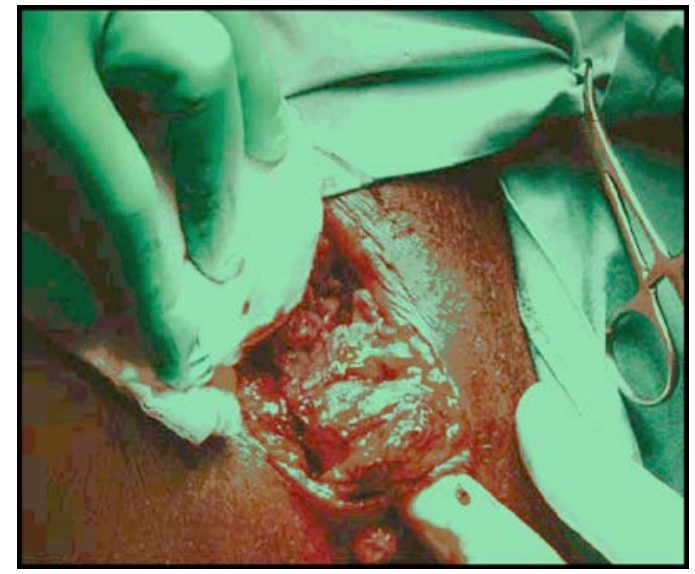

Figure (3): A partial tear along the length of the external and internal anal sphincter.

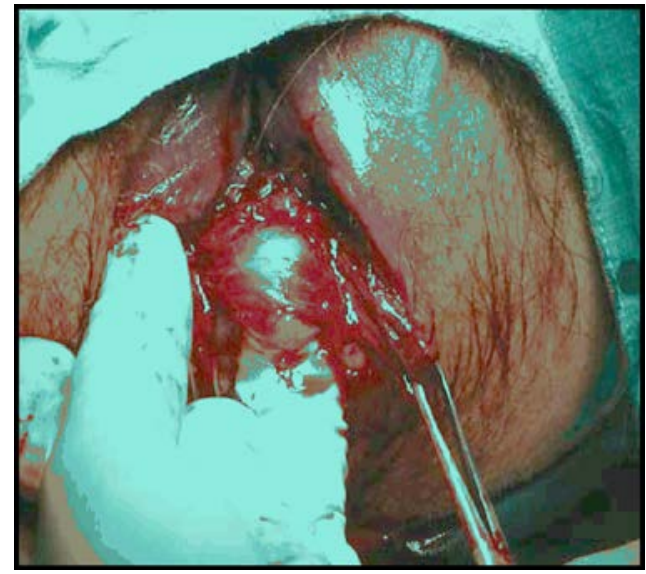

Figure (2): The torn external sphincter is shown grasped with Allis.

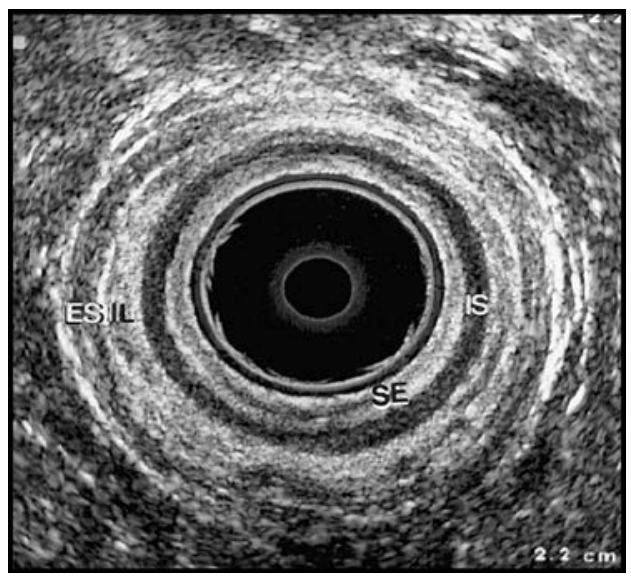

Figure (4): Transverse endoanal US image in a normal patient (GroupI). Subepithelial tissues (SE), the internal sphincter (IS), the intersphincteric space and longitudinal muscle (IL), and the external sphincter (ES) are visible.

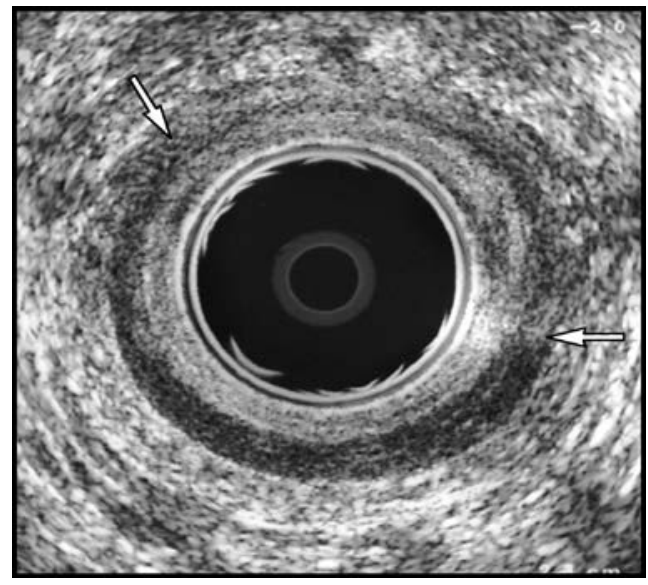

Figure (6): Anal endosonogram shows internal sphincter defect between 10-and 3-o'clock positions (arrows). 


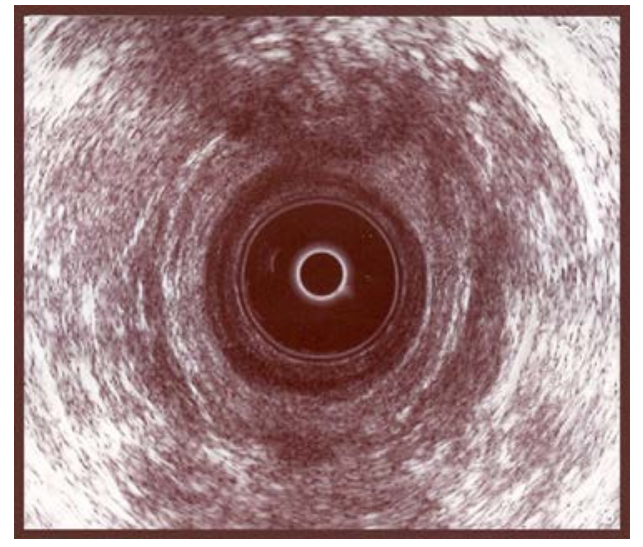

Figure (7): Anal endosonogram 3 months after repair.

\section{Discussion:}

Fecal incontinence is an embarrassing health problem that may lead to social isolation. It is reported to occur in approximately 2.2 percent of the general population. During the past decade, increasing awareness has developed that injury to the anal sphincter associated with childbirth is a major cause of the development of fecal incontinence in females. 16,19

After anal sphincter injury, up to $50 \%$ of women have complaints of faecal incontinence mainly because of persisting sphincter defects. Knowledge of possible risk factors for the occurrence of anal sphincter injuries may therefore reduce the likelihood of faecal incontinence. ${ }^{12}$

Operative vaginal delivery has been shown to be a significant contributor to the number of anal sphincter injuries. In daily obstetric practice, the use of operative vaginal deliveries is inevitable in case of fetal distress or prolonged second stage of labour. Knowledge and modification of attributive risk factors may help reduce the number of anal sphincter injuries during operative vaginal delivery. ${ }^{20-22}$

The present study describes the relationship of anal endosonography and manometry to anorectal complaints after anal sphincter injury that occurred during delivery. For comparison of the results of anal manometry and endosonography in patients who had anal sphincter damage during delivery, we sought to establish a control group of females who had an uncomplicated vaginal delivery at approximately the same time and no anorectal complaints. General and obstetric characteristics were similar between the study group and the controls.

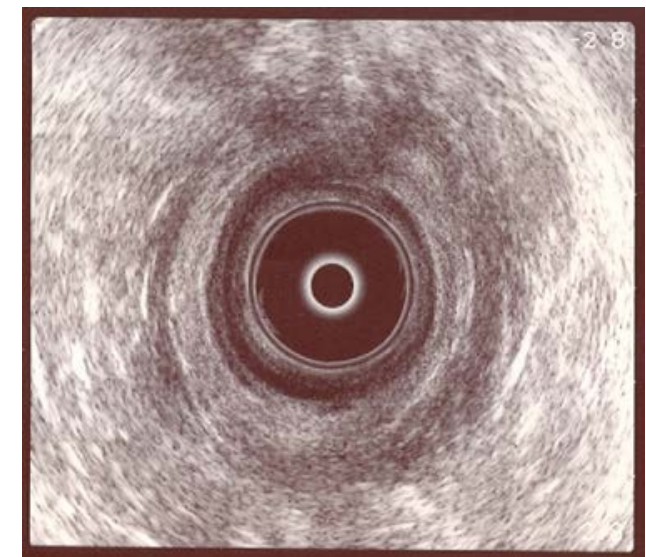

Figure (8): Anal endosonogram 1 year after repair.

Of the 100 patients in Group I with uncomplicated vaginal delivery, 13 had vaccum delivery, 8 forceps delivery, 79 had noninstrumental vaginal delivery. Ten patients $(10 / 100)$ were recognized to have sonographic signs suspicious for occult sphincter defect. Three of which, had forceps delivery (3/10), and one after vaccum delivery (1/10).

According to literature, the prevalence of occult sphincteric trauma as identified by anal endosonography is much more between 35 and $41 \% .{ }^{7,23}$

Our study has shown that clinically occult sphincter damage represents $3 / 8(37.5 \%)$ of forceps delivery, $1 / 13(7.6 \%)$ of vaccum delivery, that is $4 / 21(19 \%)$ of instrumental delivery as a whole, while $6 / 79(7.6 \%)$ of noninstrumental delivery group sustained occult anal sphincter defect.

Thus instrumental delivery is associated with more risk of developing occult anal sphincter tear and this goes with studies of Sultan \& his colleagues, Donnelly \& his colleagues, and Mac Arthur \& his colleagues; who stated that women of instrumental delivery group were at greater risk of sustaining occult anal sphincter tears than women of noninstrumental delivery group. This is probably because the application of the instrument in the vagina stretches on the perineum during vaginal delivery causing undetected anal sphincter tears. $5,7,24,25$

This study has shown that there is a good correlation between the use of forceps and prevalence of clinically undiagnosed anal sphincter tears. We found that $37.5 \%$ of women delivered by forceps had sustained occult anal sphincter defect, whereas $7.6 \%$ of women who 
delivered by vaccum extraction sustained occult anal sphincter defect.

Thus forceps delivery represents one of the greatest obstetric risk factors of sustaining clinically undetected anal sphincter damage and this agrees with studies of Faltin \& his colleagues, Mac Arthur \& his colleagues, and Morakinyo \& Spencer, they stated that women who delivered by forceps had significantly more occult trauma as identified by anal endosonography, whereas vaccum extraction was associated with less damage of anal sphincter muscles.7,23,26 These authors explained that premature extension of the head with forceps would present a larger diameter to the outlet and hence predispose to damage. By contrast vaccum extraction allows the head to rotate to a position that would allow descent along the path of least resistance. ${ }^{27,28}$

So this study and those of previous authors support recommendations by the Royal College of Obstetricians and Gynaecologists and the Cochrane review of controlled trails, that the vaccum extractor should be the instrument of choice. $^{4}$

This study has shown that occult anal spincter damage can exist even though the perineum is intact, and digital anal examination may be misleading about muscle strength and sphincter integrity. Thus the advent of anal endosonography allows the diagnosis of clinically undetected anal sphincter tears after vaginal delivery that might be associated with subsequent fecal incontinence. ${ }^{29}$

Kamm, Frudinger \& his colleagues and Zetterstrom \& his colleagues stated that the anal endosonography can accurately identify the clinically undetected anal sphincter tears and that the reliability of anal endosonography is significantly improved by limiting endoanal US to the distal $1.5 \mathrm{~cm}$ of the anal canal. $8,30-32$

In our study, 4/10 (40\%) patients of those presented with occult anal sphincter injury (as detected by endosonography) have anorectal complaints. According to Fynes \& O'Herlihy, only a small minority (32\%) of anal sphincter defects found at postpartum endosonography are associated with symptoms. ${ }^{3}$ It is suggested that such occult sphincter injuries may become symptomatic in later life. ${ }^{33}$

In this study, the fetal birth weight, length of the 2nd stage of labour, were found to be higher in those with $3 r$ degree perineal tear than in those with no defects $(\mathrm{P}<0.001$ for both). In other words, with increased birth weight there is an increased risk of perineal tear during vaginal delivery.

This agrees with studies of Kamm and Sultan \& his colleagues, who stated that one of the commonest risk factor for damage during childbirth is a large baby $\bullet 4 \mathrm{kgm}$, as this large birth weight may increase force of tension on the perineum during vaginal delivery and thus increase the risk of sustaining anal sphincter damage. ${ }^{24,30}$

Our study has shown that shoulder dystocia is associated with increased risk of anal sphincter tear; where shoulder dystocia occurred during vaginal delivery in 20\% (2/10) of those who had occult sphincter injury, and $13.3 \%$ (4/30) of those who had an overt sphincter injury. On the contrary, the study of Sultan \& his colleagues, showed that there is no significant relation between the effect of shoulder dystocia and the occurrence of 3rd degree perineal tear. ${ }^{24}$

Our study has shown that the maternal age had no significant relation to the occurrence of anal sphincteric defect. This agrees with the study of Groutz \& his colleagues who found no significant association between the maternal age and the development of anal sphincteric defect. ${ }^{34}$

MacArthur \& his colleagues found a relationship between advanced maternal age and anal incontinence symptoms. This is probably because young women who sustain trauma to the sphincter appear to have the ability to compensate and therefore some may not suffer immediate functional disturbance. ${ }^{7}$ However, with aging, other potential factors, such as, collagen weakness, pudendal neuropathy and hormonal effects of the menopause may critically compromise the anal sphincter function. ${ }^{25}$

Our study has shown that there was no association between type of labour onset and damage of anal sphincter. This result agrees with the studies of Sultan \& his colleagues, and MacArthur \& his colleagues who found no association between the onset of labour and anal sphincter defect. ${ }^{7,24}$ 
In this study, the vast majority of all episiotomies were mediolateral episiotomies, which were found to decrease the risk of developing anal sphincter injury during vaginal delivery. According to literature, the midline episiotomy is strongly associated with an increased risk for the occurrence of third- and fourth-degree perineal tears. ${ }^{12}$ However, the role of mediolateral episiotomies in operative vaginal deliveries is debated. Youssef $\&$ his colleagues reported a risk increasing effect of the use of episiotomies in operative vaginal deliveries, ${ }^{35}$ Bodner-Adler \& his colleagues reported a protective effect of mediolateral episiotomies in forceps deliveries, ${ }^{36}$ and Aukee $\&$ his colleagues reported a similar effect in vacuum extractions. ${ }^{37}$ De Leeuw \& his colleagues, reported that in both vacuum extractions and forceps deliveries, this type of episiotomy had a strongly protective effect for the occurrence of sphincter lesions. ${ }^{12}$ Several studies found no association between the episiotomy and anal sphincter tear. ${ }^{7,24}$

In this study, the results of anal manometry were significantly related to anal sphincter injury. Both MARP and MASP were significantly lower in patients with previous anal sphincter damage with complaints than in controls, although in patients with previous anal sphincter damage without complaints, only MASP differed significantly from that in controls. Haadem \& his colleagues and Sultan $\&$ his colleagues showed that MARP and MASP were significantly reduced in patients with anal sphincter damage shortly after delivery, regardless of the presence of complaints. ${ }^{38,39}$ Sorensen $\&$ his colleagues found significantly lower MARP and MASP in patients with anal sphincter damage than in controls 3 months after delivery, but these differences had disappeared 12 months after delivery. ${ }^{40}$ In the present study ultrasonographic defects in the anal sphincter complex were strongly associated with anal sphincter damage during delivery, in accordance with results of previous studies. ${ }^{16,41}$

Results of previous studies on the relationship between anorectal complaints and anal endosonography are contradictory. Some studies showed a strong association between findings of anal endosonography and the occurrence of anorectal complaints. 39,42
Whereas others found no relationship between fecal incontinence and sphincter defects. ${ }^{43}$

In the present study, our results suggest that in the evaluation of patients with anorectal complaints after anal sphincter damage during delivery, anal manometry provides additional therapeutic information when performed after anal endosonography. In the entire group of 30 subjects with $3 \mathrm{rd}$ degree perineal tear, a resting anal pressure $-30 \mathrm{mmHg}$, and ultrasound evidence of combined ES + IS defect, were significantly related to anorectal complaints.

Maximal anal squeeze pressure and ultrasound evidence of an isolated EAS defect were not found to be significantly related to anorectal complaints. The presence of an IAS defect often implies that an obstetric tear has extended through the EAS to involve the IAS, indicating a more severe injury. The majority of IAS defects in this study occurred in association with EAS defects. In addition, it can be difficult to identify the IAS muscle separately from the EAS muscle at the time of primary repair, although it has been shown that when sought out, this structure can be consistently identified as a separate structure. Thus, it may not be adequately repaired. These 2 factors may explain the positive correlation between IAS defects on endoanal ultrasound and symptoms of fecal incontinence. Our results concur with those of Sultan, and Thakar that it may be important to identify an IAS injury at the time of primary repair so that it can be repaired appropriately. ${ }^{44}$ In other words, the possibility of locating a sphincter defect (by postpartum endoanal sonography) is of clinical importance, because secondary repair is one of the therapeutic options in these patients.

Several studies reported also that there is only lowered resting pressures in patients with internal sphincter defects, whereas in patients with external sphincter defects, no difference was found with regard to maximum squeeze pressures. ${ }^{12,33,39}$

In conclusion, the most independent predictors for the anal sphincter disruption include the length of 2 nd stage if $\bullet 75 \mathrm{~min}$, absence of episiotomy, presence of shoulder dystocia, and the mode of delivery, where there is increased risk on using forceps delivery. Anal endosonography after vaginal delivery 
allows the diagnosis of clinically undetected anal sphincter damage that may be associated with subsequent fecal incontinence. It is an accurate, and reliable technique as digital anal examination may be misleading. Anal monometry is useful in assessment of anal sphincter disruption following vaginal delivery especially when combined with an endoanal ultrasonography. A prospective long term follow up study is thus recommended to discuss the true clinical impact of occult anal sphincter damage and its association with fecal incontinence. In addition, a large prospective randomized study is required to address the impact of specific situations such as failed instrumentation with the use of second instrument and the effect of rational forceps.

\section{References:}

1- Mellgren A, Jensen L, Zetterstrom J, Wong W, Hofmeister J, Lowry A: Long-term cost of fecal incontinence secondary to obstetric injuries. Dis Colon Rectum 1999; 42: 857-865.

2- Power D, Fitzpatrick M, O'Herlihy C: Obstetric anal sphincter injury: How to avoid, how to repair: A literature review. The Journal of Family Practice 2006; 55(3): 193-200.

3- Fynes M, O'Herlihy C: The influence of mode of delivery on anal sphincter injury and faecal continence. The Obstetrician \& Gynaecologist 2001; 3: 3.

4- Royal College of Obstetricians and Gynaecologists (RCOG): The management of third- and fourth-degree perineal tears. London (UK): Royal College of Obstetricians and Gynaecologists (RCOG) 2004; 11 p. (Green-top guideline; no. 29).

5- Donnelly V, O'Herlihy, Campbell D, O'Connell P: Postpartum fecal incontinence is more common in women with irritable bowel syndrome. Dis Colon Rectum 1998; 41: 586-589.

6- Fynes M, Donnelly V, Behan M, O'Connell $\mathrm{P}$, O'Herlihy: Effect of second vaginal delivery on anorectal physiology and faecal continence: A prospective study. Lancet 1999; 18; 354(9183): 983-986.

7- MacArthur C, Bick D, Keighley M: Faecal incontinence after childbirth. Br J Obstet gynecol 2001;104: 4GSO.
8- Zetterstrom J, Lopez A, Dolk A, Nornlan M, Mellgren A: Anal incontinence after vaginal delivery: A prospective study in primiparous women. Br J Obstet Gynecol 1999; 106: 324-330.

9- Donnelly V, Fynes M, Campbell D, O'Herlihy C: Obstetric events leading to anal sphincter damage. Obstet Gynecol 1999; 92: 955-961.

10-Sultan A, Kamm M, Bamam C, IIudson C: Anal sphincter trauma during instrumental delivery. Int Gynecol Obstet 1993; 43: 265-270.

11-Parvez S: Prevention and management of iatrogenic sphincter injuries. Bombay Hospital Journal 2008; Vol. 50, No. 3:416418.

12-De Leeuw J, De Wit C, Kuijken J, Bruinse $\mathrm{H}$ : Mediolateral episiotomy reduces the risk for anal sphincter injury during operative vaginal delivery. BJOG 2008; 115: 104-108.

13-Oliver R, Thakar R, Sultan A: Occult anal sphincter injuries--myth or reality? BJOG 2006; 113: 195-200.

14-Tan E, Anstee A, Koh D, Gedroyc W, Tekkis P: Diagnostic precision of endoanal MRI in the detection of anal sphincter pathology: A metaanalysis. Int J Colorectal Dis 2008; 23(6): 641-651.

15-Sentovich S, Blatchford G, Rivela L, Lin K, Thorson A, Christensen M: Diagnosing anal sphincter injury with transanal ultrasound and manometry. Dis Colon Rectum 1997; 40: 1430-1434.

16-De Leeuw J, Vierhout M, Struijk P Auwerda $\mathrm{H}$, Bac D, Wallenburg H: Anal sphincter damage after vaginal delivery: Relationship of anal endosonography and manometry to anorectal complaints. Dis colon Rectum 2002; 45(8): 1004-1010.

17-Soerensen M, Bek K, Buntzen S, Højberg $\mathrm{K}$, Laurberg S: Long-term outcome of delayed primary or early secondary reconstruction of the anal sphincter after obstetrical injury. Dis Colon Rectum 2008; 51(3): 312-317.

18-Osterberg A, Graf W, Karlbom U, Pahlman L: Evaluation of a questionnaire in the assessment of patients with fecal incontinence and constipation. Scand $J$ Gastroenterol 1996; 31: 575-580. 
19-Chaliha C, Sultan A, Stanton S: Changes in the pelvic floor following childbirth. Fetal Matern Med Rev 1999.

20-De Leeuw J, Struijk P, Vierhout M, Wallenburg H: Risk factors for third degree perineal ruptures during delivery. BJOG 2001; 108: 383-387.

21-Christianson L, Bovbjerg V, McDavitt E, Hullfish K: Risk factors for perineal injury during delivery. Am J Obstet Gynecol 2003; 189: 255-260.

22-Dandolu V, Chatwani A, Harmanli O, Floro C, Gaughan J, Hernandez E: Risk factors for obstetrical anal sphincter lacerations. Int Urogynecol J 2005;16: 304-307.

23-Faltin D, Sangalli M, Curtin F, Morabia A, Weil A: Prevalence of anal incontinence and other anorectal symptoms in women. Int Urogynecol J 2001; 12(2):117-120.

24-Sultan A, Kamm M, Hudson C, Bartram C: Third degree obstetric anal sphincter tears: Risk factors and outcome of primary repair. BMJ 1994a; 308: 887-891.

25-Sultan A, Johanson R, Carter J: Occult anal sphincter trauma following randomized forceps and vacuum delivery. Int J Gynecol Obstet 1998; 61: 11519.

26-Morakinyo E, Spencer J: Anal and urinary incontinence after childbirth. The Obstetrician and Gynaecologist 2001; 3 (1): 41-44.

27-Chaliha C, Sultan A, Boer K, Mills M, Murphy D, Wai C: Midline episiotomy and anal incontinence. BMJ 2000; 320: 16011601.

28-Signorello L, Harlow B, Chekos A, Repke J: Midline episiotomy and anal incontinence: Retrospective cohort study. BMJ 2000; 320: 86-90.

29-Faltin D, Boulvain M, Irion O, Bretones S, Stan C, Weil A: Diagnosis of anal sphincter tears by postpartum endosonography to predict fecal incontinence. Obstet Gynecol 2000; 95(5): 643-647

30-Kamm M: Fortnightly review: Faecal incontinence. BMJ 1998; 316: 528-532.

31-Frudinger A, Halligan S, Bartram C, Spencer J, Kamm M: Changes in anal anatomy following vaginal delivery revealed by anal endosonography. $\mathrm{Br} J$ Obstet Gynaecol 1999; 106(3): 233-337.

32-Kamm M: Faecal incontinence. BMJ 2003; 327: 1299-1300.
33-Titi M, Jenkins J, Urie A, Molloy R: Correlation between anal manometry and endosonography in females with faecal incontinence. Colorectal Dis 2008; 10(2): 131-137.

34-Groutz A, Lessing J, David M, Wolman I, Jaffa A, Gordon D: Incidence and obstetric risk factors of postpartum anal incontinence. Scand J Gastroenterol 1999; 34(3): 315318.

35-Youssef R, Macleod M, Murphy D: Cohort study of maternal and neonatal morbidity in relation to use of episiotomy at instrumental vaginal delivery. BJOG 2005; 112: 941-945.

36-Bodner-Adler B, Bodner K, Kimberger O, Mayerhofer K: Management of the perineum during forceps delivery: Association of episiotomy with the frequency and severity of perineal trauma in women undergoing forceps delivery. $J$ Reprod Med (2003); 48:239-242.

37-Aukee P, Sundström H, Kairaluoma M: The role of mediolateral episiotomy during labour: Analysis of risk factors for obstetric anal sphincter tears. Acta Obstet Gynecol Scand 2006;85: 856-860.

38-Haadem K, Dahlstrom J, Lingman G: Anal sphincter function after delivery: A prospective study in women with sphincter rupture and controls. Eur J Obstet Gynecol Reprod Biol 1999; 35: 7-13.

39-Sultan A, Kamm M, Talbot I, Nicholls R and Bartram C: Anal endosonography for identifying external sphincter defects confirmed histologically. Br J Surg 1994b; 81: 463-465.

40-Sorensen M, Tetzschner T, Rasmusssen O, Bjarnesen J, Christiansen J: Sphincter rupture in childbirth. Br J Surg 1993; 80: 392-394.

41-Poen A, Felt-Bersma R, Strijers R, Dekker G, Cuesta M, Meuwissen S: Third-degree obstetric perineal tear: Long-term clinical and functional results after primary repair. Br J Surg 1998; 85: 1433-1438.

42-Gjessing H, Backe B, Sahlin Y: Third degree obstetric tears: Outcome after primary repair. Acta Obstet Gynecol Scand 1998; 77: 736-740.

43-Goffeng A, Andersch B, Andersson M, Berndtsson I, Hulten L, Oresland T: Objective methods cannot predict anal 
incontinence after primary repair of extensive anal tears. Acta Obstet Gynecol Scand 1998; 77: 439-443.
44-Sultan A, Thakar R: Diagnosis of anal sphincter tears to prevent fecal incontinence: A randomized controlled trial. D Obstet Gynecol 2005; 106: 11081109. 